\title{
PLASMA INTERLEUKIN-6 LEVEL IS ASSOCIATED WITH NT-PROBNP LEVEL AND PREDICTS SHORT- AND LONG TERM MORTALITY IN PATIENTS WITH ACUTE HEART FAILURE
}

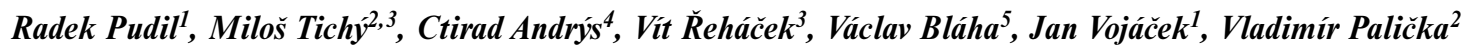

Charles University in Prague, Faculty of Medicine and University Hospital Hradec Králové, Czech Republic: $1^{\text {st }}$ Department of Medicine ${ }^{1}$, Institute of Clinical Biochemistry and Diagnostics ${ }^{2}$, Institute of Clinical Immunology and Allergology ${ }^{4}$ and Department of Transfusion Medicine ${ }^{3}$; University of Defence Brno, Faculty of Military Health Sciences Hradec Králové, Czech Republic ${ }^{5}$

\begin{abstract}
Summary: Objectives: Interleukin 6 plays an important role in chronic heart failure (HF), but little is known about its involvement in acute decompensated heart failure (ADHF). The aim of our study is to evaluate the prognostic role of interleukin 6 (IL-6) in the patients with ADHF. Methods: Plasma levels of interleukin IL-6, N-terminal pro brain natriuretic peptide levels, and clinical covariates were measured in 92 patients with ADHF. Survival was followed up to 12 months, and prognostic factors were evaluated. Results: Elevated plasma IL-6 levels were increased in nonsurvivors and were associated with 1-year mortality $(\mathrm{p}<0.01)$. Plasma IL-6 levels were associated with plasma NT-proBNP levels. In multivariate analysis, increased plasma IL-6 and NT-proBNP levels remained strong independent predictors of 1-year mortality. Conclusions: Plasma IL-6 levels provide important prognostic information in the patients with ADHF. Measurement combining plasma IL-6 and NT-proBNP should serve as a powerful prognostic tool of multimarker strategy in patients with acute decompensated heart failure.
\end{abstract}

Key words: Interleukin 6; Acute decompensated heart failure; NT-proBN; Mortality

Interleukin 6 (IL-6) is a pleitropic cytokine with a broad range of humoral and cellular immune effects. IL- 6 is produced in response to infection, IL-1, interferon gamma, and TNF $\alpha$. IL-6 has a plasma half-life less than 6 hours $(2,11)$. IL- 6 is a central mediator of the acute phase response and primary determinant of hepatic production of C-reactive protein $(6,10)$. The data about interleukin 6 and its role in chronic heart failure are already known (1). The IL-6 spillover in peripheral circulation increases with the severity of chronic congestive heart failure, and the increase of IL-6 is mainly associated with the activation of the sympathetic nervous system (15). High plasma IL-6 levels can provide prognostic information in patients with chronic congestive heart failure (CHF), independently of left ventricular function and plasma norpepinephrine, suggesting important role for IL-6 in the pathophysiology of CHF (14). High plasma IL-6 levels are associated with increased mortality. Increased plasma IL-6 level may contribute to disease progression, and be associated with enhanced mortality in patients with chronic heart failure $(2,10)$.

IL-6 plays an important role in chronic heart failure (HF) $(3,8)$, but little is known about its involvement in acute decompensated heart failure (ADHF).
The aim of our study is to evaluate the prognostic role of interleukin 6 in the patients with ADHF.

\section{Materials and Methods}

\section{Patients and controls}

A group of 92 consecutive patients aged between 22 to 85 years with acute decompensated heart failure were enrolled into the prospective observational study (Table 1). The patients presenting acute myocardial infarction (ESC/ACC criteria for the diagnosis of AMI were used), sepsis, serious lung disease, cancer, renal failure, and volume overload caused by serious renal and liver disease were excluded. The causes of heart failure were mainly coronary artery disease ( $82 \%), 11$ patients had dilated cardiomyopathy and 13 hypertension cases.

26 age- and sex-matched blood donors served as a control group. All of them were nonobese, normotensive, and free from acute diseases, and they all denied the use of any medication during the 4 weeks before the study. They all had normal plasma values for main plasma indices, nonpathologic erythrocyte and leukocyte counts, and normal urine analysis. All control subjects completed cardiologic 
examination, including electrocardiogram and echocardiographic investigation was performed. In the subjects $>50$ years of age, bicycle ergometry was performed to exclude asymptomatic heart disease.

Blood samples to measure NT-proBNP and IL-6 were obtained by venipuncture at the time of admission. Blood samples were collected into chilled tubes containing
EDTA, immediately placed on ice, and promptly centrifuged ( $2700 \mathrm{~g}$ at $4{ }^{\circ} \mathrm{C}$ for 10 minutes). After that plasma was decanted and stored in $-20{ }^{\circ} \mathrm{C}$ until assayed. Plasma IL-6 levels were measured using the Human IL-6 Immunoassay (Quantikine HS, R\&D Systems) and NT- proBNP was measured using the commercially available immunoassay based on sandwich technique (Elecsys pro BNP, Roche

Tab 1: Demographics and clinical characteristics study populations.

\begin{tabular}{|c|c|c|c|c|}
\hline & $\begin{array}{l}\text { Controls } \\
\text { (n 26) }\end{array}$ & $\begin{array}{l}\text { Patients } \\
\text { (n 92) }\end{array}$ & $\begin{array}{l}\text { Survivors } \\
(\mathrm{n}=59)\end{array}$ & $\begin{array}{c}\text { Deceased } \\
(\mathrm{n}=33)\end{array}$ \\
\hline Age, $x+$ SD & $58.74 \pm 16.75$ & $66.3 \pm 14$ & $65 \pm 16$ & $68.5 \pm 6.4$ \\
\hline Age $>60, \mathrm{n}(\%)$ & $18(69)$ & $69(75)$ & $42(71)$ & $27(81)$ \\
\hline Female, n (\%) & $9(34)$ & $27(29)$ & $18(30)$ & $9(29)$ \\
\hline BMI, $\mathrm{x} \pm \mathrm{SD}$ & $26.8 \pm 2.2$ & $27.5 \pm 2.8$ & $28.2 \pm 2.2$ & $26.4 \pm 2.1$ \\
\hline Current smoker, n (\%) & 0 & $34(37)$ & $25(42)$ & $9(28)$ \\
\hline Diabetes, n (\%) & 0 & $41(44)$ & $27(45)$ & $14(43)$ \\
\hline Arterial hypertension, $\mathrm{n}(\%)$ & 0 & $13(14)$ & $8(13)$ & $5(15)$ \\
\hline Coronary artery disease, $\mathrm{n}(\%)$ & 0 & $75(82)$ & $50(80)$ & $25(78)$ \\
\hline Prior myocardial infarction, n (\%) & 0 & $50(54)$ & $35(58)$ & $15(45)$ \\
\hline Dilated cardiomypathy & 0 & $11(12)$ & $5(8)$ & $6(18)$ \\
\hline Atrial fibrillation, $\mathrm{n}(\%)$ & 0 & $26(28)$ & $18(30)$ & $8(25)$ \\
\hline Heart rate $(\mathrm{bpm}), \mathrm{x} \pm \mathrm{SD}$ & $76 \pm 9$ & $122 \pm 21$ & $119 \pm 18$ & $124 \pm 22$ \\
\hline Systolic BP $(\mathrm{mmHg}), \mathrm{x} \pm \mathrm{SD}$ & $128 \pm 12$ & $138 \pm 23$ & $142 \pm 16$ & $133 \pm 19$ \\
\hline Diastolic BP $(\mathrm{mm} / \mathrm{Hg}), \mathrm{x} \pm \mathrm{SD}$ & $75 \pm 7$ & $89 \pm 18$ & $95 \pm 8$ & $86 \pm 9$ \\
\hline Ejection fraction $\%$ & $63.65 \pm 5.1$ & $34.3 \pm 14^{* *}$ & $35 \pm 14$ & $31.8 \pm 12.9$ \\
\hline IL-6 $(\mathrm{pg} / \mathrm{mL})$ & $2.4 \pm 1.5$ & $30.1 \pm 22.28 *$ & $26 \pm 16$ & $37.9 \pm 23.6^{+}$ \\
\hline $\begin{array}{l}\text { NT-proBNP }(\mathrm{pg} / \mathrm{mL}), \text { median, } \\
\text { interquartile range }\end{array}$ & $\begin{array}{c}78 \\
(54-110)\end{array}$ & $\begin{array}{c}6277 * * \\
(2639-11562)\end{array}$ & $\begin{array}{c}3811 \\
(2566-6377)\end{array}$ & $\begin{array}{c}10985^{++} \\
(8861-19846)\end{array}$ \\
\hline Creatinine $(\mu \mathrm{mol} / \mathrm{L})$ & $86.2 \pm 11.6$ & $144.8 \pm 44.2^{*}$ & $126.2 \pm 18$ & $155 \pm 21^{+}$ \\
\hline
\end{tabular}

${ }^{*} \mathrm{p}<0.01$ vs. controls; ${ }^{* *} \mathrm{p}<0.001$ vs. controls; ${ }^{+} \mathrm{p}<0.01$ vs. survivors; ${ }^{++} \mathrm{p}<0.001$ vs. survivors

Tab 2: Clinical characteristics of study population according to quartiles of IL-6.

\begin{tabular}{|c|c|c|c|c|c|c|}
\hline & All & Q1 & Q2 & Q3 & Q4 & $\mathrm{P}_{\text {trend }}$ \\
\hline & patients & $(2.7-10.48)$ & $(10.48-27.9)$ & $(27.9-56)$ & $(56-68.7)$ & \\
\hline Age, $\mathrm{x} \pm \mathrm{SD}$ & $66.3 \pm 14$ & $71.3 \pm 13$ & $62.2 \pm 16.7$ & $64.7 \pm 11.9$ & $66.9 \pm 12$ & \\
\hline Age>60, n (\%) & $69(75)$ & $21(91)$ & $14(60)$ & $15(65)$ & $19(82)$ & \\
\hline Female, n (\%) & $27(29)$ & $9(39)$ & $6(26)$ & $3(13)$ & $9(39)$ & \\
\hline BMI, $\mathrm{x} \pm \mathrm{SD}$ & $27.5 \pm 2.8$ & $28.1 \pm 2.8$ & $26.3 \pm 3.1$ & $27.3 \pm 2.6$ & $25.6 \pm 3.1$ & \\
\hline Current smoker, n (\%) & $34(37)$ & $8(34)$ & $11(47)$ & $9(39)$ & $6(26)$ & \\
\hline Diabetes, n (\%) & $41(44)$ & $12(52)$ & $8(34)$ & $9(39)$ & $12(52)$ & \\
\hline Arterial hypertension, $\mathrm{n}(\%)$ & $13(14)$ & $4(17)$ & $4(17)$ & $3(13)$ & $2(8)$ & \\
\hline Coronary artery disease, $\mathrm{n}(\%)$ & $75(82)$ & $19(82)$ & $17(73)$ & $19(82)$ & $20(87)$ & \\
\hline Prior MI, n (\%) & $50(54)$ & $12(52)$ & $9(29)$ & $15(65)$ & $14(60)$ & \\
\hline Dilated cardiomypathy & $11(12)$ & $4(17)$ & $3(13)$ & $1(4)$ & $4(17)$ & \\
\hline Heart rate $(\mathrm{bpm}), \mathrm{x} \pm \mathrm{SD}$ & $122 \pm 21$ & $135 \pm 22$ & $115 \pm 26$ & $125 \pm 23$ & $136 \pm 21$ & \\
\hline Systolic BP $(\mathrm{mmHg}), \mathrm{x} \pm \mathrm{SD}$ & $138 \pm 23$ & $140 \pm 28$ & $145 \pm 30$ & $132 \pm 18$ & $139 \pm 23$ & \\
\hline Diastolic BP $(\mathrm{mm} / \mathrm{Hg}), \mathrm{x} \pm \mathrm{SD}$ & $89 \pm 18$ & $92 \pm 15$ & $89 \pm 21$ & $94 \pm 9$ & $91 \pm 14$ & \\
\hline Atrial fibrillation, $\mathrm{n}(\%)$ & $26(28)$ & $8(34)$ & $5(21)$ & $5(21)$ & $8(34)$ & \\
\hline Ejection fraction $(\%)$ & $34.3 \pm 14$ & $37.3 \pm 13.6$ & $30.3 \pm 14.3$ & $32.6 \pm 13.6$ & $36.5 \pm 14$ & \\
\hline $\begin{array}{l}\text { NT-proBNP }(\mathrm{pg} / \mathrm{mL}) \text { median } \\
\text { (interquartal range) }\end{array}$ & $\begin{array}{c}6277 \\
(2639-11562)\end{array}$ & $\begin{array}{c}2882 \\
(1746-4638)\end{array}$ & $\begin{array}{c}6164 \\
(2022-8755)\end{array}$ & $\begin{array}{c}10284 \\
(4955-26360)\end{array}$ & $\begin{array}{c}10895 \\
(6380-27760)\end{array}$ & 0.001 \\
\hline Creatine $(\mu \mathrm{mol} / \mathrm{L})$ & $144.8 \pm 44.2$ & $140.3 \pm 42$ & $131.2 \pm 36$ & $148.5 \pm 54.9$ & $159 \pm 36$ & \\
\hline 1-year survival n (\%) & $59(69)$ & $19(83)$ & $16(69)$ & $14(61)$ & $10(43)$ & 0.01 \\
\hline
\end{tabular}


Diagnostics). The analytical range extended from 20 to $35000 \mathrm{pg} / \mathrm{mL}$.

Echocardiography was performed according to the guidelines of the American Society of Echocardiography within two hours from the admission.

The data on history, physical examination, echocardiography, laboratory findings, and 28-day follow-up period were prospectively collected for all patients. One-year mortality data were obtained from the registry of our hospital and from the physicians of the patients.

All subjects have given their informed consent. The study protocol conforms to the ethical guidelines of the 1975 Declaration of Helsinki, and has been approved by The Ethical Committee of our institution.

\section{Statistical analysis}

Statistical evaluation was performed with Statistica 5 software. All values are expressed as mean $\pm \mathrm{SD}$; the median and range of values are also provided for data with nonnormal distribution. For quantitative data, statistical comparisons were performed using unpaired t tests for normal distributions, and the Wilcoxon test for nonnormal distributions. For qualitative data, $\chi^{2}$ test was used. The correlations between procedural variables and plasma levels were performed using linear regression analysis and Spearman correlation tests. Survival curves were generated by the means of Kaplan-Meier estimates. To evaluate mortality data, relative risks and 95 percent confidence intervals were calculated as hazard ratios derived from the Cox proportional model. Multiple regression analysis were fitted with the use the clinical covariates. A $p$ value $<0.05$ was considered significant.

\section{Results}

\section{Clinical characteristics of study population}

As shown in Table 1, the main cause of heart failure was coronary artery disease ( $82 \%)$.

There was no medication in the control group. Pharmacological treatment of ADHF patients consisted of diuretics in all patients, iv. nitrates in 26 (28\%) pts, and catecholamines were used in 9 (10\%) patients. Pre-discharge medication consisted of betablockers in 54 (58 \%) patients, angiotensin-converting enzyme inhibitor/angiotensin receptor blockers in $59(61 \%)$ patients. Mechanical ventilation was used in $12(13 \%)$ patients and non-invasive ventilation in $4(5 \%)$ patients. Aspirin was used in 75 (82\%) patients with coronary artery disease and statins were used in patients with hyperlipidemia.

\section{Plasma IL-6, NT-proBNP levels and clinical characteristics in patients with $\mathrm{ADHF}$}

Plasma IL-6 levels were significantly elevated in the patients with ADHF when compared with healthy controls $(30.4 \pm 22 \mathrm{pg} / \mathrm{mL}$ vs. $2.4 \pm 1.5 \mathrm{p}<0.01)$. The median NTproBNP level for all patients was significantly elevated $(6$
$277 \mathrm{pg} / \mathrm{mL}$; interquartile range, 2639 to 11562 vs. controls $78 \mathrm{pg} / \mathrm{mL}$; interquartile range, 54 to $110 ; \mathrm{p}<0.0001)$. Left ventricle ejection fraction was significantly decreased (34.3 $\pm 14 \%$ vs. $63.65 \pm 5.1 \%, \mathrm{p}<0.001$ )

Significant positive correlation existed between plasma IL-6 and NT-proBNP levels $(r=0.51, p<0.01, n=92)$. The analysis of echocardiography data revealed no significant association between left ventricle ejection fraction $(r=-0.09$, $\mathrm{n}=92$ ).

Relationship between plasma IL-6 level and mortality

During 1-year follow-up, 33 of 92 patients (35\%) died. Baseline characteristics associated with one-year mortality are shown in Table 1. The baseline plasma levels of IL-6 and NT-proBNP were significantly higher in the group of the patients who died during the follow-up, whereas age, gender, diabetes, and ejection fraction were not significantly different in survivors and nonsurvivors.

In order to assess the predictive value of IL-6 in plasma, the patients were divided into subgroups according to quartiles of IL-6. We analyzed clinical variables and mortality rates across the quartiles of IL-6 (Table 2). Patients with IL-6 in the upper quartile have had significantly higher plasma NT-proBNP and plasma creatinine level. Mortality rates were increasing across the IL-6 quartiles.

Kaplan-Meier estimates of survival for all subjects according to quartiles of IL-6 are shown in Figure 1.

Univariate Cox analysis showed that NT-proBNP and IL-6 were significant univariate predictors of mortality. After entering both of these parameters into a multivariate proportional model that included age, sex, creatinine level, ejection fraction, diabetes, smoking, hyperlipidemia, they remained significant independent predictors of mortality (NT-proBNP: $p=0.001$; IL-6: $p=0.02$ ).

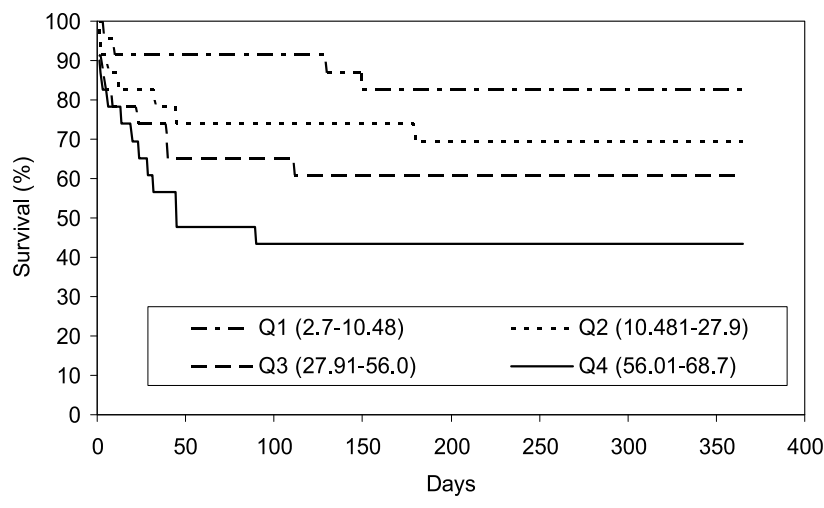

Fig. 1: Overall survival among the patients with acute decompensated heart failure, according to quartiles of IL-6. The IL-6 levels were as follows: first quartile, less than $10.48 \mathrm{pg} / \mathrm{mL}$; second quartile, 10.48 to $27.9 \mathrm{pg} / \mathrm{mL}$; third quartile, 27.9 to $56 \mathrm{pg} / \mathrm{mL}$; and the fourth quartile, more than $56 \mathrm{pg} / \mathrm{mL}$. P $<0.01$ by the $\log$ rank test for the overall comparison among the groups. 


\section{Discussion}

This pilot study demonstrates that the increase of IL-6 level in patients with acute decompensated heart failure is associated with NT-proBNP levels and provides prognostic information on mortality from all causes.

Plasma NT-proBNP levels were analyzed in a high number of studies underlying the prognostic importance of NT-proBNP assessment in patients with chronic congestive and acute heart failure $(4,5,7)$.

The assessment of natriuretic peptides has become a good standard for risk stratification and prognosis assessment in patients with acute and chronic heart failure (13, 14). Little is known about the association of NT-proBNP with cytokines.

Current data support the theory of the contributory role of cytokines (IL-6) in chronic and acute heart failure (14). Prognostic significance of increased IL-6 levels has been shown in large multicenter studies, but only a few studies focus on IL-6 in acute heart failure.

These studies showed association between increased proinflammatory cytokine levels and increased mortality $(4,12)$.

In our study, we demonstrate the prognostic significance of increased plasma IL-6 level. This statement is supported by the following facts: first, the baseline levels of IL-6 were significantly higher in nonsurvivors than in survivors; second, Kaplan-Meier analyses showed that patients' survival decreased as a function of increasing levels of interleukin 6; third, multivariate Cox proportional model showed that circulating IL-6 level was the significant independent predictor of mortality.

Our study demonstrates the association between plasma IL-6 and NT-proBNP levels. Plasma NT-proBNP levels were also significantly increased in nonsurvivors compared to survivors. Also, Cox regression model showed that plasma NT-proBNP level remained the independent prognostic factor.

Association between interleukin 6 and NT-proBNP were demonstrated by the linear regression analysis, correlation coefficient and increasing value of NT-proBNP in IL-6 quartiles.

\section{Conclusions}

Plasma interleukin 6 levels provide novel and prognostic information in the patients with ADHF. Combining measurements of interleukin 6 and NT-proBNP seem to be a promising tool in the prognostic assessment of these patients.

\section{Acknowledgements}

The study was supported by the research projects of the Charles University Prague No. MSM0021620817 and MZO 00179906.

\section{References}

1. Deswal A, Petersen N, Feldman A, Young J, White B, Mann D. Cytokines and cytokine receptors in advanced heart failure. An analysis of the cytokine database from the vesnarinone trial. Circulation 2001; 103: 2055-2059.

2. Dolci A, Pathegini M. The exciting story of cardiac biomarkers: from retrospective detection to gold diagnostic standard for acute myocardial infarction and more. Clin Chim Acta 2006; 179-187.

3. El-Meynar A, MBch B. Cytokines and Myocardial Dysfunction: State of Art. J Cardiac Fail 2008; 14: 61-64.

4. Chen D, Assad-Kottner C, Orrego C, Torre-Amione G. Cytokines and acute heart failure. Crit Care Med. 2008;36(1 Suppl): S9-16.

5. Januzzi JL, Camargo CA, Anwarudin S. The N-terminal Pro-BNP investigation of dyspnea in the emergency department (PRIDE) study. Am J Cardiol. 2005; 95(8): $948-54$

6. Joulin O, Pettilot P, Labalette M. Cytokine profile of human septic shock serum inducing cardiomycyte contractile dysfunction. Physiol Res 2007; 56: 291-7.

7. Kavsak PA, Ko DT, Newman AM, Palomaki GE et al. Risk stratification for heart failure and death in an acute coronary syndrome population using inflammatory cytokines and N-terminal pro-brain natriuretic peptide. Clin Chem. 2007; 53(12): 2112-8

8. Mehra VC, Ramgolam VS, Bender J. Cytokines and cardiovascular disease. J Leukoc Biol 2005; 78: 805-818.

9. Ndrepepa G, Braun S, Mehilli J, Schömig A, Kastrati A: Accuracy of N-Terminal Probrain Natriuretic Peptide to Predict Mortality or Detect Acute Ischemia in Patients with Coronary Artery Disease. Cardiology 2008; 109: 249-257.

10. Pathan N, Hemingway CA, Alizadeh AA. Role of interleukin 6 in myocardial dysfunction of meningococcal septic shock. Lancet 2004; 363: 203-9.

11. Petersen JW, Felker GM. Inflammatory biomarkers in heart failure. Congest Heart Fail. 2006; 12(6): 324-8.

12. Pudil R, Krejsek J, Pidrman V, Gregor J, Tichy M, Bures J. Inflammatory response to acute myocardial infarction complicated by cardiogenic shock. Acta Medica (Hradec Kralove) 2001; 44 (4): 149-51.

13. Rehman SU, Januzzi JL jr. Natriuretic peptides for guiding heart failure therapy. Compr Ther. 2008; 34: 32-40.

14. Tanner H, Mohacsi P, Fuller-Bicer GA et al. Cytokine activation and disease progression in patients with stable moderate chronic heart failure. J Heart Lung Transplant. 2007; 26: 622-9.

15. Tsutamoto T, Hisagana T, Wada A et al. Kinoshita M: Interleukin-6 spillover in the peripheral circulation increases with the severity of heart failure, and the high plasma level of interleukin-6 is an important prognostic predictor in patients with congestive heart failure. J Am Coll Cardiol. 1998; 31: 391-8.

\section{Corresponding author:}

Prof. Radek Pudil, MD, PhD, $1^{\text {st }}$ Dept. of Medicine, Charles University Prague, Faculty of Medicine, Sokolska 581, 50005 Hradec Kralove, Czech Republic; e-mail: pudilradek@yahoo.com 